\title{
The Microstructure of Copper Zinc Oxide Catalysts - Bridging the Materials Gap
}

\author{
T. Ressler*, B.L. Kniep, I. Kassatkine, R. Schlögl \\ Department of Inorganic Chemistry, Fritz-Haber-Institute of the MPG, Faradayweg 4-6, 14195 Berlin, Germany
}

*Corresponding author: e-mail ressler@fhi-berlin.mpg.de, fax +49 3084134405

** Financial support from the German Research Foundation (DFG SPP 1091) is acknowledged. We are grateful to

$\mathrm{K}$. Weiss for his assistance with the TEM measurements.

Received: 15 December 2004; Revised: 26 January 2005

\begin{abstract}
Copper zinc oxide catalysts prepared similar to industrially used catalysts were studied by high-resolution electron microscopy. The microstructure of the $\mathrm{Cu} / \mathrm{ZnO}$ catalysts deviates considerably from that of bulk copper metal and idealized copper model systems. In order to reveal reliable structure-activity relationships for copper catalysts in methanol chemistry, future model systems need to take the "real" structure of active copper catalysts into account.
\end{abstract}

Keywords: Heterogeneous catalysis, structure-activity relationships, transmission electron microscopy, copper, methanol, real structure, materials gap

\section{Introduction}

The progressing shift in resources used in the petrochemical industry from crude oil to natural gas increases the importance of methanol as a basic chemical for the production of synthetic fuels and polymers. In most recent MegaMethanol ${ }^{\circledR}$ plants that produce methanol in an excess of 5000 tons per day, supported copper nanoparticles are employed as highly active heterogeneous catalysts. For an efficient use of natural resources a knowledge-driven design of more active and selective catalysts is required. However, structure-activity relationships are often deduced from model systems exhibiting structural characteristics very different from those of industrial catalysts. Here we report insights to the microstructure ${ }^{1}$ of copper nanoparticles on zinc oxide prepared similar to industrially used copper catalysts and exhibiting comparable catalytic activities.

Supported copper nanoparticles are active catalysts for a number of methanol reactions including methanol synthesis, methanol oxidation, and methanol steam reforming. Structure-activity relationships of copper catalysts have been studied extensively on a variety of materials ranging from single crystal model systems to multiple component industrial catalysts with copper concentrations of more than $50 \%$.
2 Several suggestions were made as to the nature of the "real" structure ${ }^{3}$ of the copper phase under reaction conditions including the simplifying assumption that the activity increases linearly with the copper surface area. ${ }^{4}$ Conversely, copper nanoparticles have recently been shown to exhibit surfaces with different catalytic activities and, in addition to the surface area, bulk structural parameters like microstrain in the copper particles were identified to correlate with the catalytic activity of $\mathrm{Cu} / \mathrm{ZnO}$ catalysts in methanol synthesis and methanol steam reforming. 5, 6,7

Microscopic evidence of the nature of the "real" structure of the most active copper catalysts remains scarce. ${ }^{8,9,10}$ High-resolution transmission electron microscopy (TEM) and in situ TEM studies have been performed on copper particles supported on $\mathrm{ZnO}$ with a copper concentration of less than $10 \%$. ${ }^{11,12}$ These studies showed faceted wellordered $\mathrm{Cu}$ particles on a large and well-defined $\mathrm{ZnO}$ support. Changes in the morphology of the $\mathrm{Cu}$ particles, the ratio of the copper facets, and the surface area upon varying the reduction potential of the gas phase were impressively illustrated by in situ TEM. However, these copper model systems were prepared by impregnation of $\mathrm{ZnO}$ crystals with a solution of $\mathrm{Cu}$-acetate. This preparation procedure deviates considerably from the preparation of industrially used catalysts ${ }^{13}$ and, hence, the well-defined model systems 
The Microstructure of Copper Zinc Oxide Catalysts - Bridging the Materials Gap, T. Ressler et al., Angew.Chem.Int.Ed. 44 (2005) 4704-4707 studied probably exhibit a microstructure different from that of a catalyst prepared for an industrial application. Industrial $\mathrm{Cu} / \mathrm{ZnO} / \mathrm{Al}_{2} \mathrm{O}_{3}$ catalysts are commonly prepared by precipitating copper zinc hydroxycarbonates from metal nitrate solutions. In addition to the precipitation, each step in the subsequent treatment of the precipitate and the resulting oxide precursor (i.e. ageing, washing, drying, calcination, and reduction) affects the microstructure of the active copper phase (chemical memory). Precipitate ageing, for instance, strongly influences the activity of the resulting $\mathrm{Cu} / \mathrm{ZnO}$ catalysts. ${ }^{14,15,16,17}$ The superior activity of $\mathrm{Cu} / \mathrm{ZnO}$ catalysts obtained from precipitates aged for more than 30 min was shown to correlate with the increasing microstrain in the copper nanoparticles. ${ }^{18}$ Apparently, extrapolating structure-activity relationships revealed for idealized copper model systems to the microstructure and catalytic properties of industrial catalysts needs to be conducted with care.

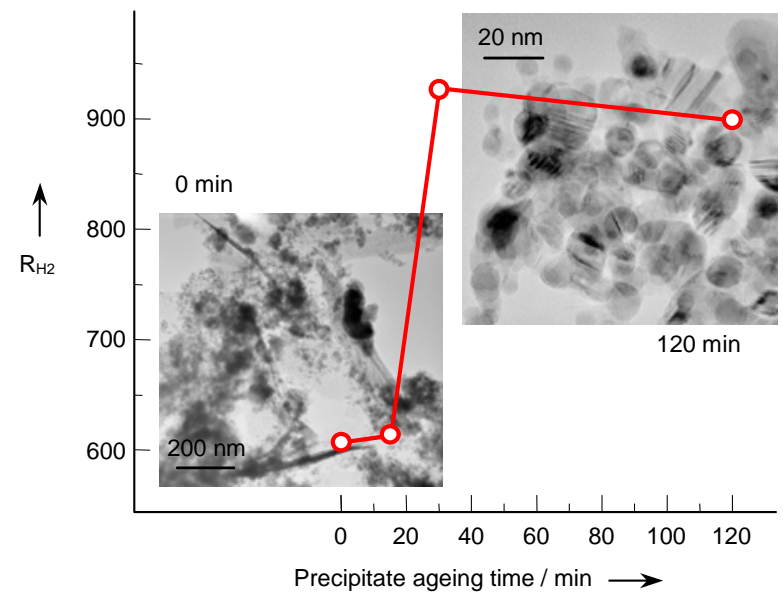

Figure 1: Transmission electron micrographs of $\mathrm{Cu} / \mathrm{ZnO}$ catalysts obtained from hydroxycarbonate precipitates aged for 0 min and 120 min together with the $\mathrm{H}_{2}$ production rate $\mathrm{R}_{\mathrm{H} 2}$ [ $\mu \mathrm{mol} \mathrm{g}-1 \mathrm{~s}-1$ ] of four catalysts as a function of precipitate ageing time (methanol synthesis activity and ageing time exhibited a similar correlation).

Here we report high-resolution transmission electron microscopy investigations of the microstructure of reduced $\mathrm{Cu} / \mathrm{ZnO}$ catalysts obtained from differently aged hydroxycarbonate precipitates. Electron micrographs of $\mathrm{Cu} / \mathrm{ZnO}$ catalysts obtained from a non-aged ( 0 min) and an aged (120 min) precipitate are depicted in Figure 1 together with the corresponding catalytic activity in the steam reforming of methanol. Electron diffraction and electron energy loss spectroscopy identified only $\mathrm{Cu}$ and $\mathrm{ZnO}$ as majority phases in the samples studied. Various morphologies of $\mathrm{Cu}$ and $\mathrm{ZnO}$ particles were detected in the $\mathrm{Cu} / \mathrm{ZnO}$ catalyst obtained from non-aged precipitates, such as large isolated $\mathrm{Cu}$ particles, large $\mathrm{ZnO}$ plates and needles, and to a lesser degree nanostructured $\mathrm{Cu}$ and $\mathrm{ZnO}$ particles (Figure 1). After $30 \mathrm{~min}$ of precipitate ageing, a transition to a homogeneous microstructure of the corresponding $\mathrm{Cu} / \mathrm{ZnO}$ catalysts was observed. In the $\mathrm{Cu} / \mathrm{ZnO}$ catalysts obtained from precipitates aged for more than $30 \mathrm{~min}$, mostly nanostructured $\mathrm{Cu} / \mathrm{ZnO}$ particles were found with only minute amounts of isolated $\mathrm{Cu}$ or $\mathrm{ZnO}$ particles detectable (Figure 1). The increase in

catalytic activity observed for $\mathrm{Cu} / \mathrm{ZnO}$ catalysts obtained ${ }^{2}$ from precursors aged for more than $30 \mathrm{~min}$ (Figure 1) clearly correlates with the distinct change in the microstructure of the catalysts. While the less active $\mathrm{Cu} / \mathrm{ZnO}$ catalysts comprise a heterogeneous mixture of large and isolated $\mathrm{Cu}$ and $\mathrm{ZnO}$ particles, the more active catalysts show small and intimately mixed $\mathrm{Cu}$ and $\mathrm{ZnO}$ particles. The homogeneous microstructure of the more active $\mathrm{Cu} / \mathrm{ZnO}$ catalysts may constitute a potential lead for future preparations of improved catalysts for methanol chemistry.

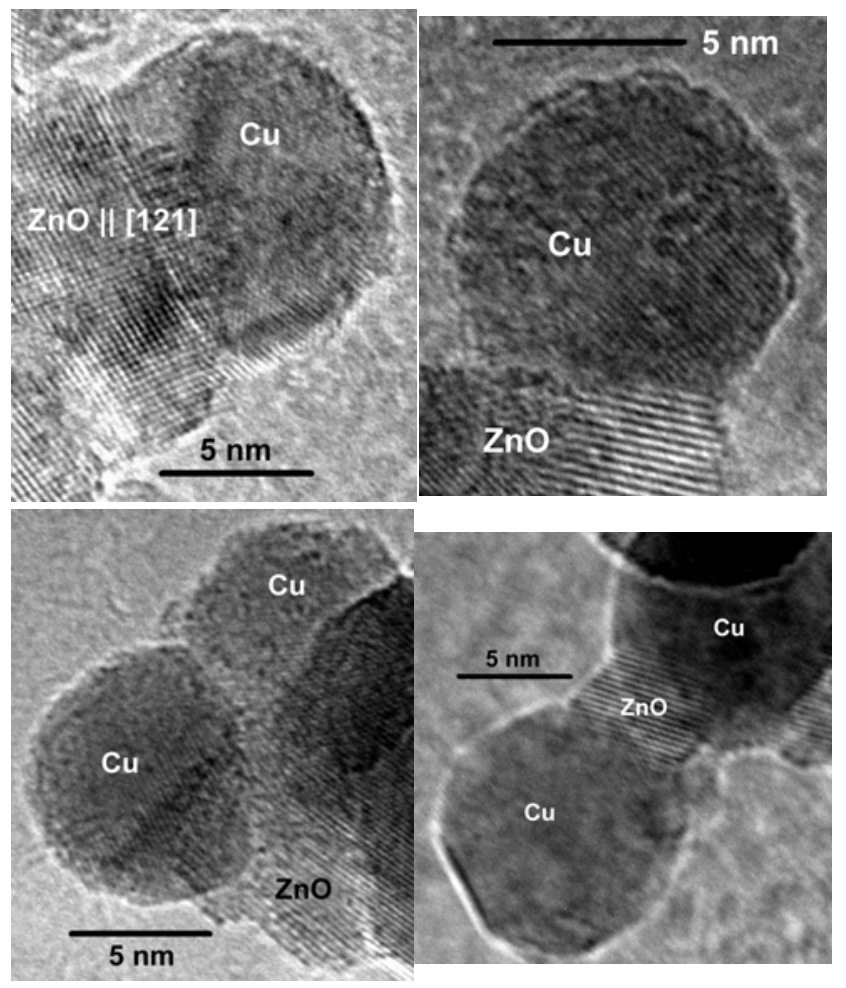

Figure 2: High-resolution transmission electron micrographs of a $\mathrm{Cu} / \mathrm{ZnO}$ catalyst obtained from a copper zinc hydroxycarbonate precipitate aged for $120 \mathrm{~min}$.

High-resolution electron micrographs show a marked interface between the $\mathrm{Cu}$ and $\mathrm{ZnO}$ particles (Figure $2 \mathrm{~A}$ and B). Well-defined copper clusters on large $\mathrm{ZnO}$ particles, like the ones observed in the model systems described above, ${ }^{11}$ are clearly absent in $\mathrm{Cu} / \mathrm{ZnO}$ catalysts prepared similar to industrially used copper catalysts. The $\mathrm{Cu}$ and $\mathrm{ZnO}$ particles in the $\mathrm{Cu} / \mathrm{ZnO}$ catalysts obtained from longer-aged precipitates are round-shaped (Figure 2) or oval-shaped independent of their size. The high-resolution micrographs reveal a variety of epitaxial relations between $\mathrm{Cu}$ and $\mathrm{ZnO}$ (e.g. $\mathrm{Cu}[110]\|\mathrm{ZnO}[100], \mathrm{Cu}[111]\| \mathrm{ZnO}[100]$, Figure 2 and Figure 3) with an average contact angle between the $\mathrm{Cu}$ and $\mathrm{ZnO}$ particles of $\sim 61^{\circ}$. Zinc oxide exhibits a higher degree of structural order than the copper nanoparticles in the reduced $\mathrm{Cu} / \mathrm{ZnO}$ catalyst (Figure 2), while the distinct defects in the $\mathrm{ZnO}$ structure may be indicative for the oxygen deficient nature of the $\mathrm{ZnO}$ particles in the catalysts. Moreover, $\mathrm{ZnO}$ particles are often found to be located between $\mathrm{Cu}$ particles, thus efficiently preventing them from sintering (Figure $2 \mathrm{C}$ and D). 
of copper surface area and catalytic activity in methanol chemistry, is a strong evidence for the existence of additional bulk or surface structural parameters that govern the activity of copper nanoparticles. ${ }^{5,6,7}$ The superior interface between the $\mathrm{Cu}$ particles and the $\mathrm{ZnO}$ support in the homogeneous microstructure of the more active $\mathrm{Cu} / \mathrm{ZnO}$ catalysts, can be correlated to the previously reported increased degree of strain in the $\mathrm{Cu}$ particles in the highly active $\mathrm{Cu} / \mathrm{ZnO}$ catalysts as determined by averaging bulk structural techniques (XRD, NMR). ${ }^{18}$ Thus, the higher degree of disorder in the $\mathrm{Cu}$ nanoparticles, which corresponds to an increased deviation from the "ideal" structure of bulk copper metal, results from an increased interface area between $\mathrm{Cu}$ and $\mathrm{ZnO}$ and is indicative of a more active copper catalysts.

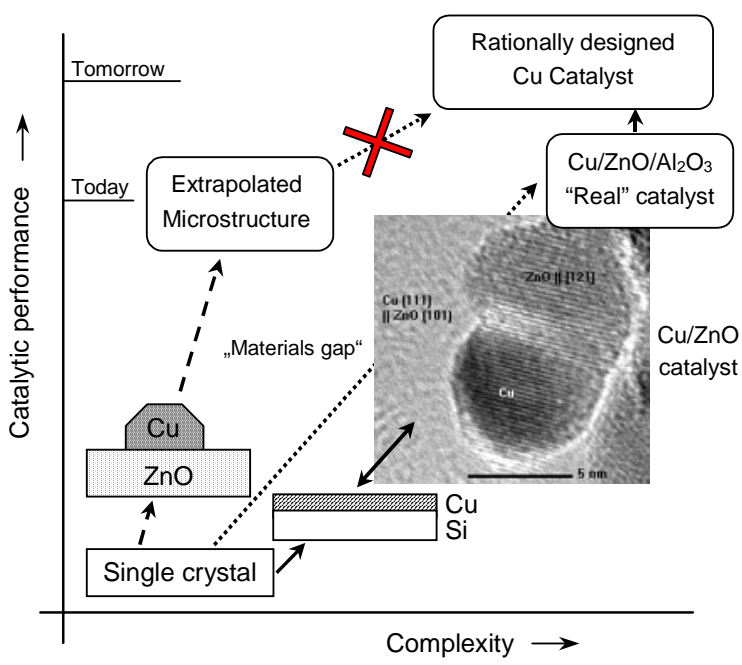

Figure 3: Schematic representation of the relationship between structural complexity and catalytic performance and the requirement of suitable model systems to bridge the materials gap between the structure-activity correlations for industrial copper catalysts and the microscopic understanding of elemental process on catalyst surfaces.

The $\mathrm{Cu} / \mathrm{ZnO}$ catalysts described here exhibit a reduced complexity with respect to the most active industrial $\mathrm{Cu} / \mathrm{ZnO} / \mathrm{Al}_{2} \mathrm{O}_{3}$ catalysts and, thus, constitute suitable model systems to investigate the microstructure of copper nanoparticles in methanol synthesis catalysts (Figure 3). The microscopic processes on the surfaces of heterogeneous catalysts are difficult to unravel from investigations of industrial catalysts because of their huge complexity and multipleparameter dependence of catalytic properties. Hence, a detailed understanding of heterogeneous catalysis on an atomistic level will most likely arise from investigations of model systems that reduce the complexity of the system and permit elucidating the influence of individual structural parameters on catalytic properties. Bridging the materials gap in heterogeneous catalyst often refers to going from the least complex model systems to the most complex industrial catalysts (Figure 3). However, from the results described here it emerges that a two-way bridge is to be built going not only from simple models to complex catalysts but also from complex systems to simplified model catalysts. Therefore, new and ing to established structure-activity relationships of copper catalysts prepared similar to industrially used catalysts (Figure 3). These second-generation model systems have to take the deviation from the ideal copper structure into account to arrive at a meaningful representation of microscopic processes in catalysis. On the one hand, model systems that closely resemble ideal bulk copper metal may be of limited value in advancing our understanding of the "real" structure of methanol catalysts under reaction conditions and designing suitable preparation routes to improved copper catalysts (Figure 3). On the other hand, copper catalysts obtained by a wet-chemical preparation appear to be less suited mostly because of the inherent difficulty to vary the "real" structure of the resulting materials without changing other relevant structural or chemical parameters (e.g. chemical composition or copper crystallite size). Thin copper films on substrates such as silicon or polyimide, for instance, are currently considered as suitable model systems (Figure 3). These systems permit dynamically adjusting the microstrain in the copper by thermal treatment or mechanical force, respectively, to elucidate the corresponding effect on the electronic structure and the catalytic properties of the copper surface. ${ }^{19,20}$

The "real" structure of the copper catalysts described here deviates considerably from that of ideal bulk copper metal and emphasizes that structural complexity is a prerequisite for an active heterogeneous catalyst. Hence, in order to reveal an atomistic understanding of catalytic reactions, second generation model systems are required that reduce complexity yet take the characteristic "real" structure of active copper catalysts into account. Eventually, this will bridge the materials gap and provide the basis for a knowledge-driven improvement of heterogeneous catalysts.

\section{Experimental}

\section{Preparation of Cu/ZnO catalysts}

Copper zinc hydroxycarbonate precursors of $\mathrm{Cu} / \mathrm{ZnO}$ catalysts with a molar ratio of copper to zinc of 70 to 30 were prepared according to a conventional co-precipitation route. ${ }^{16}$ The co-precipitation was performed in a reaction container filled with $400 \mathrm{ml}$ bidistilled water (353 K) by simultaneous mixing of an aqueous solution of metal nitrates $\left(\mathrm{Cu}\left(\mathrm{NO}_{3}\right)_{2} * 3 \mathrm{H}_{2} \mathrm{O}\right.$ and $\left.\mathrm{Zn}\left(\mathrm{NO}_{3}\right)_{2} * 6 \mathrm{H}_{2} \mathrm{O}\right)$ with sodium carbonate $(1.2 \mathrm{M})$ at constant $\mathrm{pH}$ 7. The resulting precipitates were aged under continuous stirring in the mother liquor at $353 \mathrm{~K}$ for $0 \mathrm{~min}, 15 \mathrm{~min}, 30 \mathrm{~min}$, and $120 \mathrm{~min}$. After filtering the precursors were washed six times with deionized water $(80 \mathrm{ml})$ under continuous stirring at $333 \mathrm{~K}$. Finally, the samples were dried at $393 \mathrm{~K}$ for $10 \mathrm{~h}$ in static air followed by calcination at $603 \mathrm{~K}$ in static air for $3 \mathrm{~h}$ (heating ramp $=6 \mathrm{~K} / \mathrm{min}$ ). The resulting $\mathrm{CuO} / \mathrm{ZnO}$ materials were reduced in 2.0 vol- $\% \mathrm{H}_{2}$ at $523 \mathrm{~K}$ for 30 min (heating ramp $=6 \mathrm{~K} / \mathrm{min}$ ) to obtain the $\mathrm{Cu} / \mathrm{ZnO}$ catalysts. 
Transmission electron microscopy was performed on a Phillips CM 200 FEG TEM. The reduced $\mathrm{Cu} / \mathrm{ZnO}$ catalysts were deposited on holey-carbon films supported on gold grids. The sample preparation was conducted in a glove box to prevent exposure of the reduced $\mathrm{Cu} / \mathrm{ZnO}$ catalysts to air.

\section{References}

[1] In addition to the crystallography, the "microstructure" of the material also includes those morphological features that are revealed by a microscopic examination of a suitably prepared specimen sample (from "Microstructural Characterization of Materials” by D. Brandon and W.D. Kaplan, John Wiley \& Sons (1999)).

[2] Hansen, J.B., Handbook of Heterogeneous Catalysis; Ertl, G., Knoezinger, H., Weitkamp, J., Eds.; VCH Weinheim, Vol. 4 (1997).

[3] In addition to the "ideal (crystallographic) structure" of copper metal, the "real structure" comprises all defects such as strain, impurities, etc. present in the bulk structure of the copper catalysts.

[4] G.C. Chinchen, K.C. Waugh, D.A. Whan, Appl. Catal. 1986, 25, 101.

[5] K.C. Waugh, Catal. Lett. 1999, 58, 163.

[6] M.M. Günter, T. Ressler, B. Bems, C. Büscher, T. Genger, O. Hinrichsen. M. Muhler R. Schlögl, Catal. Lett. 2001, 71, 37.

[7] M. Kurtz, H. Wilmer, T. Genger, O. Hinrichsen, M. Muhler, Catal. Lett. 2003, 86, 77.

[8] S. Metha, G.W. Simmons, K. Klier, R.G. Herman, J. Catalysis 1979, 57, 339.

[9] J.M. Dominquez, G.W. Simmons, K. Klier, J. Mol. Catal. 1983, 20, 369.

[10] G.J. Millar, I.H. Holm, P.J.R. Uwins, J. Drennan, J. Chem. Soc. Faraday Trans. 1998, 94, 593.

[11] P.L. Hansen, J.B. Wagner, S. Helveg, J.R. Rostrup-Nielsen, B.S. Clausen, H. Topsoe, Science 2002, 295, 2053.

[12] J.B. Wagner, P.L. Hansen, A.M. Molenbroek, H. Topsoe, B.S. Clausen, S. Helveg, J. Phys. Chem. B 2003, 107, 7753.

[13] Industrial $\mathrm{Cu} / \mathrm{ZnO} / \mathrm{Al}_{2} \mathrm{O}_{3}$ catalysts for methanol synthesis may contain more than $50 \%$ copper and are commonly prepared by co-precipitating mixed metal hydroxycarbonates from metal nitrate solutions.

[14] D. Waller, D. Stirling, F.S. Stone, M.S. Spencer, Faraday Disscuss. 1989, 87, 107.

[15] S.H. Taylor, G.J. Hutchings, A.A. Mirzaei, Chem. Commun. 1999, 1373.

[16] D.M. Whittle, A.A. Mirzaei, J.S.J. Hargreaves, R.W. Joyner, C.J. Kiely, S.H. Taylor, G.J. Hutchings, PCCP 2002, 4, 5915.

[17] B. Bems, M. Schur, A. Dassenoy, H. Junkes, D. Herein, R. Schlögl, Chem. Eur. J. 2003, 9, 2039.

[18] B.L. Kniep, T. Ressler, A. Rabis, F. Girgsdies, M. Baenitz, F. Steglich, R. Schlögl, Angewandte Chemie Int. Ed. 2004, 43, 112.

[19] M. Hommel, O. Kraft, E. Arzt, J. Mater. Res. 1999, 14, 2373.

[20] R.M. Keller, S.P. Baker, E. Arzt, J. Mater. Res. 1998, 13, 1307. 